Historic, Archive Document

Do not assume content reflects current scientific knowledge, policies, or practices. 



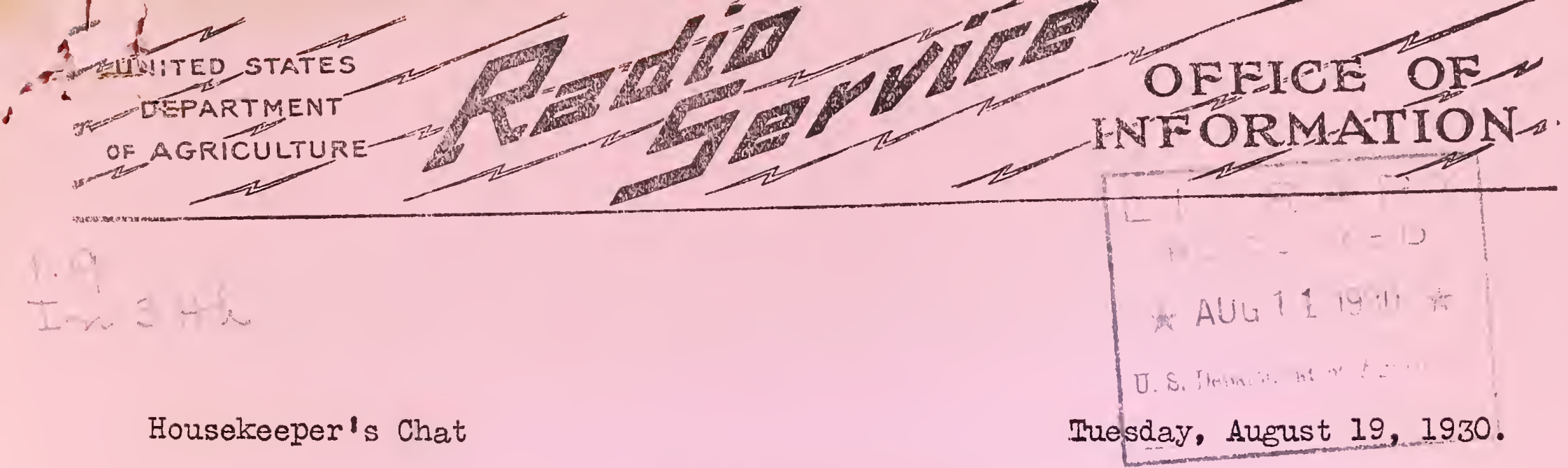

\section{NOT FOR PUBLICATION}

Subject: "Questions and Answers." Approved by the Bureau of Home Economics, U.S.D.A. Bulletin available: "Fleas and Their Control."

$-00000-$

The first question today is about crickets. Which reminds me of the earliest poem I ever compused. It was all about being sad and lonely. I was twelve years old at the time, and the poem was inspired by the merry chirping of a cricket which seemed to mock my efforts to be melancholy. One can be so melancholy at the age of twelve?

My correspondent writes: "Te have been greatly annoyed lately by crickets getting into our house. I don't suppose they do any damage, but the noise they make is irritating, and I dont know how to get rid of them. The lawn and the neighborhood generally seem to be alive with them."

Unfortunately orickets are not entiroly harmless. They do some damage to furnishings, and if very prevalent, they are a really destructive pest. They will eat curtains, or garments, or book bindings, or rugs, especially if these are wet or moist. They often breed in great numbers in garbage or dumps near houses. Perhaps there's some place of the kind in your locality. And whether you hear them inside the house or in the yard nearby, they make a most annoying noise. Perhaps some of us have attached too much sentiment to the thought of a cricket because Charles Dickens wrote a story called "The Cricket on the Hearth."

I asked our Bureau of Entomology what to do about cridkets. This was what I was told: "The most effective way to get rid of crickets permanently is to have breeding spots, such as garbage dumps, cleaned up entirely or treated with waste oil. Infested rooms may be relieved of the presence of some of these noisy visitors by the use of poisoned baits.

"Dissolve 1 tablet of bichloride of mercury in one-half cup of water and then add one-half cup of flour and stir well into a paste. Cut into small pieces the skin of a banana and mix into the pasto. Thon spread small quantities on cardboard, and place about the infested room. Talse care to keep the bait out of reach of children and pets."

Sounds like a "banana split" for crickots, doesn't it? And I'd like to add that if you have a summer cottage or camp, it would be a good idea to look out for crickets when you close it up for the winter. You inght put a few poisoned baits around in suitable Iocations. Pack bedaing or wearing apparel left over the winter in tight boxes or trunks, just as you would to protect thom from moths and other insect pests. 
$l_{1}^{\prime}=4$ 


\section{$\mathrm{R} \rightarrow \mathrm{HC}$}

My next question is also about insects. "My dog used to sleep at the foot of my boy's bed until I found out that he had fleas. Now the room is infested with them. That shall I do?" That's the trouble with animal pets, isn't it? Eut both the room and the dog can be rid of the fleas with a little patience.

The rugs or carpet must be taken out of doors and cleaned, and then sprayed with benzine or gasoline. The floors should be washed with soapsuds, especially the cracks between boards and along raseboards. The dog needs a good washing with one of the saponified coal-tar preparations known as "stock-dips." There are a number on the market. He should be thoroughly scrubbed in a tub, especially on his head, where the fleas rush to get away from the water. After he has been in the bath 5 or 10 minutes he may be removed and allowed to dry.

There is a bulletin on "Fleas and Their Control" which you might send for if you have any further trouble.

Somehow the mention of fleas reminds me of a poem Billy once learned. He has a passion for alliteration -- rhymes with/same letter running through them.

A flea and a fly once met in a flue.

Said the $f l y$, "Let us flee."

Said the flea, "Let us fly."

So they flew through a flaw in the flue."

One reason I ljke that poem is that it explains so much about our troubles with household insects. If it isn't a flaw in the flue, a flaw in the housekeeping accounts for the presence of a good many household pests. Most of them go where they can find their preferred fond. Some want crumbs, scraps, garbage, and other foods; others want woolens and furs, and some want human blood. The last groupsin which the commonest pests are mosquitoes, fleas, and bedbugs- has to be combated by measures that destroy the places where they live and breed. Fumigation is sometimes an extreme remedy for a number of insect pests. Perhaps I should have included wood ticks and chiggers among the insects that annoy human beings, but they are not encountered in houses.

A housekaeper who keeps her supplies in tight motal or glass containers and who cleans up scattered food crumb promptly, has relatively little trouble with roaches, ants, weevils, and other food-eating insects. The garbage pail is a brceding place for flies as well as crickets and other insects. Needless to say, it should be kept closed at all times, emptied regularly, and rinsed out each time it is emptied. Iining the garbage pail with clear paoer I have found to be a great help in keeping it clean without mus work.

Here is a question about okra. It is from a woman who lives in Now York City, who has never seen okra growing. "I heard so much about dera from southern friends, so I got some and cooked it like other vegetables, in boiling salted rater. It seemed tos much like slippery elm. My husband wouldn't eat it. Is there any other way I coula prepare olrra?" 


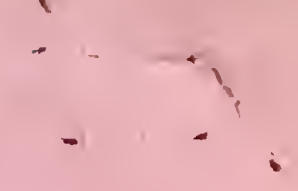

$\therefore$

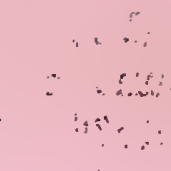

$\therefore \square, \therefore \quad \therefore \quad \therefore$

: 
Answer: Try fried olrra. Select about 2 quarts of young olrra pods, wash them well, and trim off the stems close to the pods. Cut the olra crosswise, in pieces about half an inch thick. Heat 4 tablespoons of nice smeet fat in a heavy skillet, add the olrra, cover, cook for 10 minutes, and stir frequently to prevent burning. Remove the cover, and continue to cook until the okra is tender and lightly brown. Serve at once.

I think everybody likes olrra cooked in this way. Southerners use a great deal of okra in their soups and "gumbos", becuase of its distinctive flavor. The okra that you boiled would have made a fine soup if you had combined it with some tomatoes and meat broth about equal parts of each, and cooked them all together.

TOMORROW, we'll talk about Children's Pocket Money. FEDNESDAY: "The School Child's Allowance." 

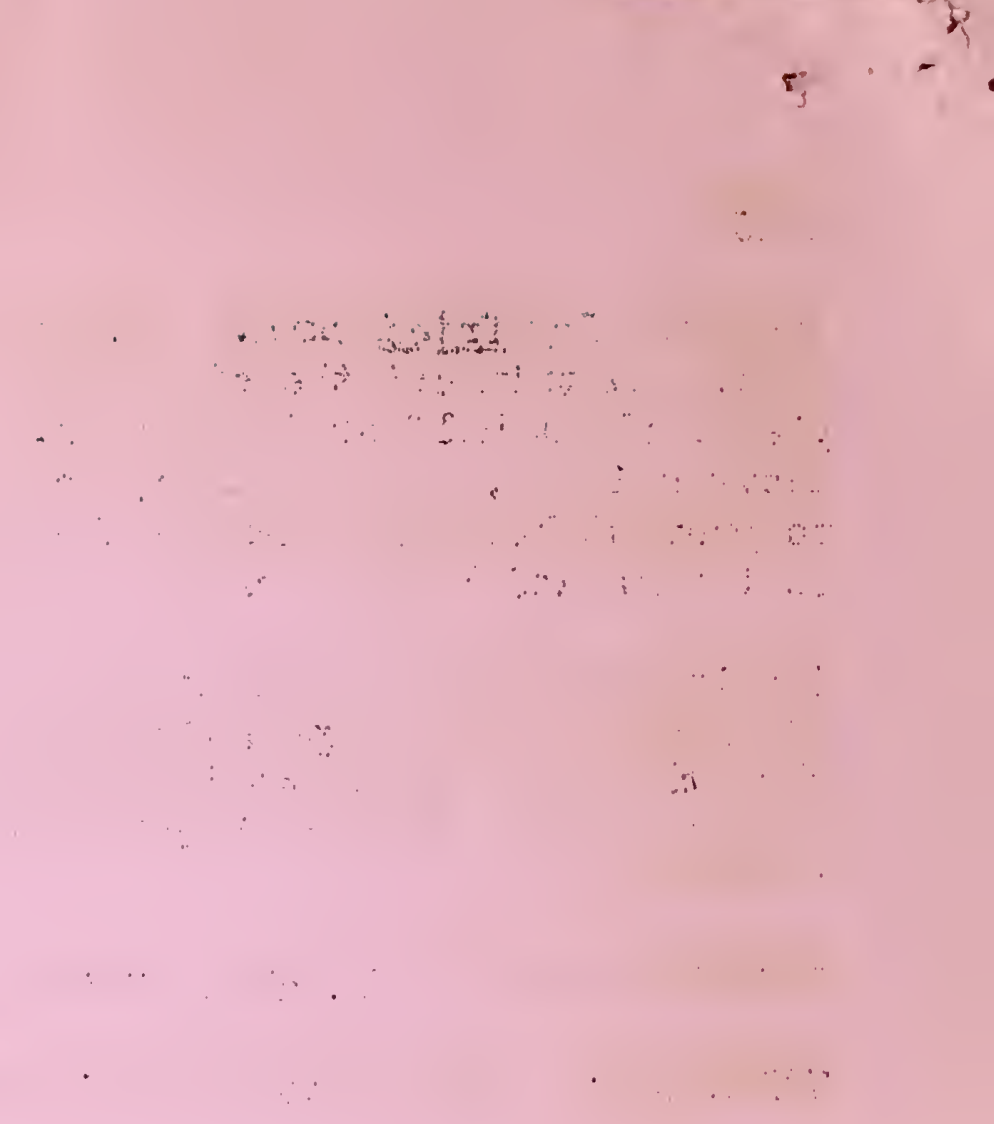